\title{
A Mechanical DCCB with Re-Closure Capability and Its Performance in MMC based DC Grid
}

Binye Ni, Wang Xiang*, Meng Zhou, Xiaojun Lu, Wenping Zuo, Wei Yao, Jinyu Wen

State Key Laboratory of Advanced Electromagnetic Engineering and Technology, Huazhong University of Science and Technology, Wuhan 430074, China

Abstract- For the modular multilevel converter (MMC) based DC grids using overhead line transmission, to restore the power transmission quickly, the DC circuit breakers (DCCB) are required to be able to re-close after DC line faults. To meet this requirement, an improved mechanical DCCB topology with re-closure capability is proposed in this paper. It consists of a pre-charged capacitor, an auxiliary capacitor, an oscillation inductor, and anti-parallel thyristors. Firstly, the topology and operating principle of the mechanical DCCB are presented in detail. Then, the general sizing methods associated with the impact of parameters on interruption capability are disclosed. The feasibility of the proposed mechanical DCCB is validated in a stiff DC system. Finally, the transient performance of the DC grid embedding the proposed mechanical DCCBs is investigated under various operating scenarios. The results verify the DC fault interruption and fast automatic re-closure capabilities of the proposed DCCB. It is shown that the mechanical DCCBs can be well applied to the overhead MMC based HVDC grids systems.

Key Words - DC grid, mechanical DC circuit breaker (DCCB), DC fault clearance, automatic reclosure, energy dissipation.

\section{INTRODUCTION}

With the increasing demand for large scale renewable energy utilization, the modular multilevel converter (MMC) based DC grid technology is widely recognized as a promising approach for long distance power transmission [1]-[4].

To deal with the DC faults on overhead lines, the high power DC circuit breakers (DCCB) are adopted to isolate the faulty lines [5][6]. On detecting DC faults, DCCBs will be tripped to interrupt the fault current 
within several milliseconds, which avoids the blocking of converters and realizes un-interrupted power transmission of the DC grid [7]. Among the various DCCB technologies, the hybrid DCCBs based on fast mechanical switch and full-controlled power electronic devices are conventionally considered as the most suitable solution [8]-[11]. Some prototypes of hybrid DCCB have been developed, such as the DCCBs with transfer branches consisting of full-bridge sub-modules and diode bridges [12][13]. These two prototypes will be applied in the $\pm 500 \mathrm{kV}$ Zhangbei DC grid project [14], which is the first MMC based DC grid in the world. However, according to the bidding results of this project, the cost of hybrid DCCBs accounts for about $20.1 \%$ of total investment, which is very close to the cost of valves (33.4\%) [15]. The high cost of DCCBs hampers the further development of DC grid technology.

In order to reduce the cost of hybrid DCCB, some researches propose several improved topologies, such as the DCCBs disclosed in [16][17]. These topologies introduce an uncharged commutation capacitor in the main branch to make the cost economically competitive. However, these improved topologies still suffer from relatively large conduction power loss. An alternative scheme is to adopt mechanical DCCBs. Unlike hybrid DCCBs, the mechanical DCCBs utilize inductors and pre-charged capacitors to generate an oscillated current and create a zero crossing point in the fault current. Since no full-controlled power electronic devices are used, the capital cost and power loss can be significantly reduced. But the traditional mechanical DCCBs have the problem of long interruption time (more than $10 \mathrm{~ms}$ ) [18]-[19], failing to meet the high-speed requirement of MMC-HVDC systems.

Recently, with the development of mechanical switch technology, the interruption time of mechanical DCCBs is much improved [20]-[22]. References [23]-[24] propose a coupling mechanical DCCB topology, which has the interruption capability and speed comparable to the hybrid DCCBs. The commutation branch of the mechanical DCCB is consisted of a low-voltage triggering circuit and a high-voltage oscillation circuit. When DC faults happen, the triggering circuit will generate a pulse current and an oscillation current will be induced at the high-voltage side through the coupling reactors. In 2017, this DCCB has been successfully put into operation in the $\pm 160 \mathrm{kV}$ Nan'ao three-terminal HVDC project. 
Similar to AC grids, for the MMC based DC grids using overhead transmission lines, the transmission system operator (TSO) requires the DCCB to automatically re-close after fault isolation to ensure fast recovery of power transmission. For instance, in Zhangbei project, the DCCBs will automatically re-close within $300 \mathrm{~ms}$ [14]. If DCCBs re-close to permanent faults, they will trip again. However, since it is difficult to recharge the pre-charged capacitor within the reclosing time, the commissioned mechanical DCCBs are not able to re-close when instantaneous faults occur.

To overcome the technical defects of the existing mechanical DCCBs, this paper proposes a mechanical DCCB with re-closure capability. It consists of a pre-charged capacitor, an auxiliary capacitor, an oscillation inductor, and anti-parallel thyristors. Different from the coupling mechanical DCCBs proposed in [23]-[24], the pre-charged capacitor can be recharged by discharging the auxiliary capacitor to obtain the re-closure capability. Compared with the mechanical DCCB proposed in [25], this DCCB replaces the switches in commutation branch by thyristor valve to increase the operation speed. Besides, without the use of extra precharged capacitor, the proposed DCCB has advantages in both cost and volume. The detailed comparisons between the proposed DCCB with typical existing DCCB topologies are shown in Table I. As can be seen, the proposed DCCB is more appropriate for the DC grid using overhead lines.

Table I The comparisons the proposed DCCB with existing DCCB topologies

\begin{tabular}{|c|c|c|c|c|c|c|c|c|c|}
\hline Categories & \multicolumn{4}{|c|}{ Hybrid DCCB } & \multicolumn{5}{|c|}{ Mechanical DCCB } \\
\hline Publications & {$[10]-[11]$} & [12] & [13] & [17] & [20] & [25] & [23] [24] & [26] [27] & \multirow[b]{2}{*}{$\begin{array}{l}\text { The } \\
\text { proposed } \\
\text { topology }\end{array}$} \\
\hline Topologies & $\begin{array}{c}\text { Inverse } \\
\text { IGBTs } \\
\text { submodule } \\
\end{array}$ & $\begin{array}{l}\text { Full-bridge } \\
\text { submodule }\end{array}$ & $\begin{array}{c}\text { Diode- } \\
\text { bridge } \\
\text { submodule } \\
\end{array}$ & $\begin{array}{l}\text { Capacitor } \\
\text { commutated }\end{array}$ & $\begin{array}{l}\mathrm{LC} \\
\text { resonant }\end{array}$ & $\begin{array}{c}\text { Extra switch } \\
\text { and } \\
\text { capacitor }\end{array}$ & $\begin{array}{l}\text { Coupling } \\
\text { topology }\end{array}$ & $\begin{array}{l}\text { LC-Bridge } \\
\text { topology }\end{array}$ & \\
\hline $\begin{array}{l}\text { Interruption } \\
\text { theory }\end{array}$ & \multicolumn{3}{|c|}{$\begin{array}{l}\text { Use full-controlled power electronic } \\
\text { devices to commutate and interrupt } \\
\text { fault current }\end{array}$} & $\begin{array}{c}\text { Use } \\
\text { capacitor to } \\
\text { commutate } \\
\text { current }\end{array}$ & \multicolumn{5}{|c|}{$\begin{array}{l}\text { Use pre-charged capacitor to inject inverse current to interrupt } \\
\text { fault current }\end{array}$} \\
\hline $\begin{array}{l}\text { Operation } \\
\text { time }\end{array}$ & $2.4 \mathrm{~ms}$ & $\leqslant 3 \mathrm{~ms}$ & $\leqslant 3 \mathrm{~ms}$ & $3.21 \mathrm{~ms}$ & $3 \sim 4 \mathrm{~ms}$ & $10 \mathrm{~ms}$ & $\leqslant 5 \mathrm{~ms}$ & About $3 \mathrm{~ms}$ & About $3 \mathrm{~ms}$ \\
\hline \multirow{2}{*}{$\begin{array}{l}\text { Re-Closure } \\
\text { Capability }\end{array}$} & $\sqrt{ }$ & $\sqrt{ }$ & $\sqrt{ }$ & $\sqrt{ }$ & \multirow[b]{2}{*}{$x$} & \multirow[b]{2}{*}{$\sqrt{ }$} & & \multirow[b]{2}{*}{$x$} & \multirow[b]{2}{*}{$\sqrt{ }$} \\
\hline & \multicolumn{4}{|c|}{$\begin{array}{l}\text { More arresters (MOVs) should be installed to } \\
\text { facilitate re-closure capability }\end{array}$} & & & & & \\
\hline Cost & (due t & $\begin{array}{c}\text { High } \\
\text { expensive IC }\end{array}$ & BTs) & \begin{tabular}{|c|} 
Lower than \\
{$[10]-[13]$} \\
\end{tabular} & \multicolumn{2}{|c|}{$\begin{array}{l}\text { Lower than hybrid } \\
\text { DCCB }\end{array}$} & \multicolumn{2}{|c|}{ Lower than typical topology } & \begin{tabular}{|c|} 
Higher than \\
{$[23]-[27]$} \\
\end{tabular} \\
\hline $\begin{array}{l}\text { Conduction } \\
\text { loss }\end{array}$ & \multicolumn{4}{|c|}{$\begin{array}{c}\text { High } \\
\text { (due to IGBTs in LCS) }\end{array}$} & \multicolumn{5}{|c|}{ Low } \\
\hline Volume & \multicolumn{4}{|c|}{ Small } & \multicolumn{5}{|c|}{$\begin{array}{l}\text { Larger than hybrid DCCB } \\
\text { (due to pre-charged capacitor) }\end{array}$} \\
\hline
\end{tabular}

The remainder of this paper is organized as follows. Firstly, the system layout of the MMC based DC grid 
is introduced in section II. Then, the operating principle and dynamics during the operation of the proposed DCCB are analyzed in section III. The parameters design of the main circuit components of this DCCB is discussed in section IV. Then, the performance and effectiveness of the DCCB are verified by the simulations in section V. Finally, the performance of the four-terminal meshed DC grid embedding the proposed DCCB is studied in section VI. And the conclusion is drawn in section VII.

\section{DC Fault Management OF The MMC BASEd DC GRID}

The topology of a bipolar four-terminal meshed DC grid is shown in Fig. 1. Each converter employs the half-bridge sub-modules based MMC topology. The DCCBs and current limiting inductors are installed on both terminals of the overhead lines.

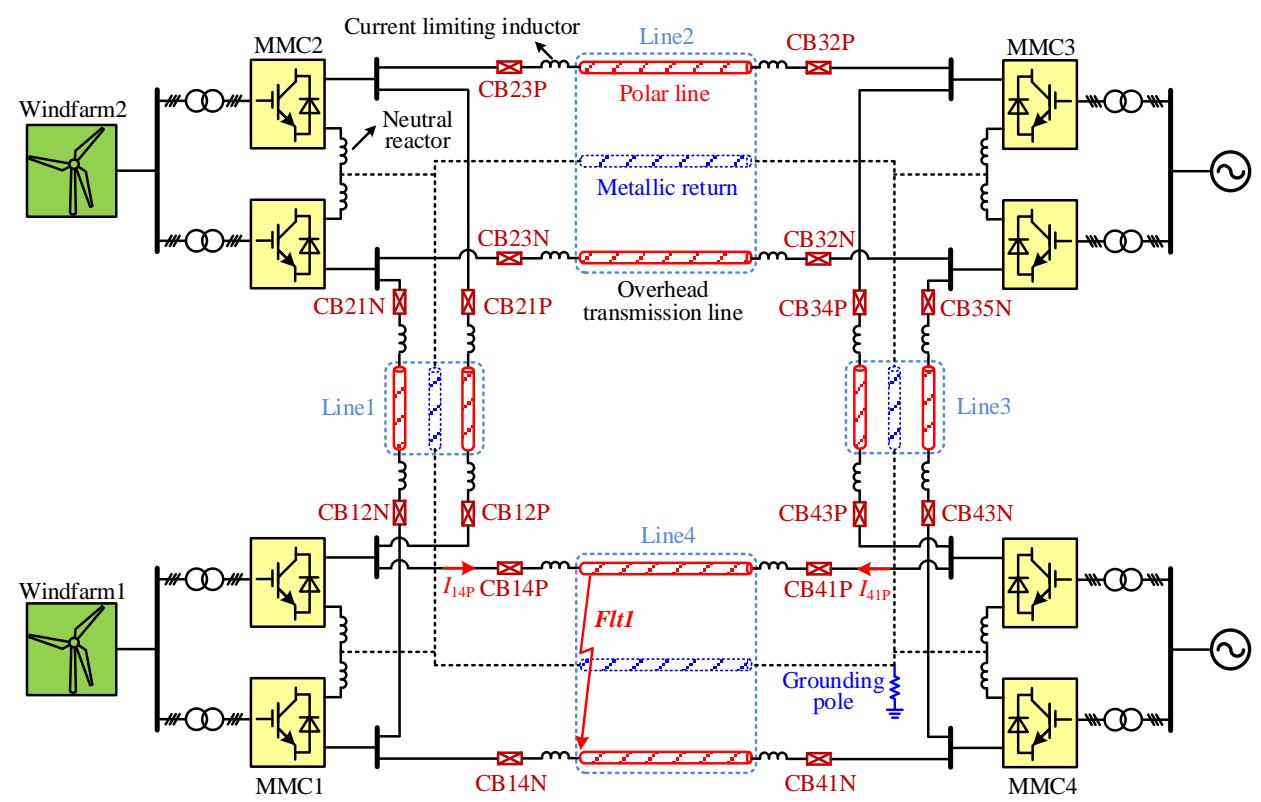

Fig. 1. The structure of a bipolar four-terminal MMC-based DC grid with mechanical DCCB.

The DC fault management sequence of the meshed overhead DC grid is shown in Fig. 2. When a DC fault occurs, the protection system sends the tripping orders to DCCBs on the faulty lines within 2-3 ms delay [28][29]. Then, the DCCBs trip and the fault current begins to decrease within 2-3 ms. After sufficient deionization of DC lines (200-300 ms) [14], the DCCBs automatically re-close. If the fault still exists, the line current will increase rapidly again. The DCCBs are considered to re-close to a permanent DC fault and immediately trip again. 


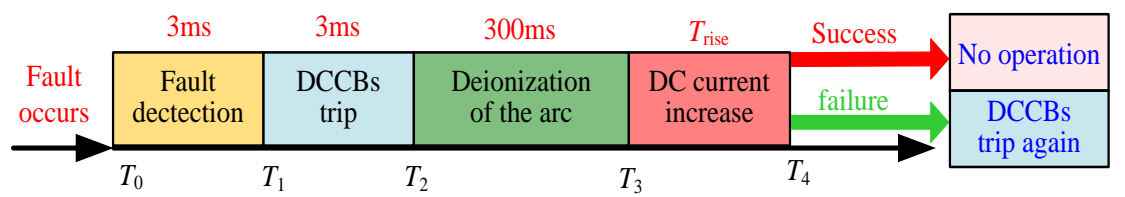

Fig. 2. The sequence of DC fault management for overhead DC grid.

\section{Topology of Mechanical DCCB With Re-Closure CAPABILITY}

\section{A. Re-closure Problem of the Existing Mechanical DCCB}

The topology of a coupling mechanical DCCB is shown in Fig. 3. Similar to the conventional mechanical DCCB, this topology also consisted of the mechanical switch (MS), metal oxide varistors (MOVs), thyristors and a pre-charged capacitor. It adopts a triggering circuit at the low-voltage side, which reduces the withstanding voltages of the components and further reduces the cost of DCCB.

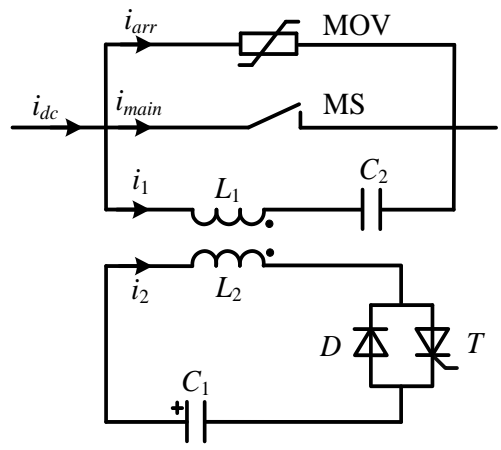

Fig. 3 Structure of the coupling mechanical DC circuit breaker.

However, the coupling mechanical DCCB also suffer from the problem of capacitor recharging during reclosing. After the DCCB interrupts the fault current, the voltage of the pre-charged capacitor may drop to 0 or even be opposite to the initial value. Due to the limited capacity of the charge circuit, it is impossible to charge the capacitor voltage to the initial value within the reclosing time (200-300ms). Therefore, the coupling mechanical DCCB lacks the re-closure capability and is not applicable to the DC grid using the overhead lines.

B. Mechanical DCCB with Re-closure Capability and its Operating Principle

To meet the requirement of post-fault re-closure, this paper proposes an improved topology of mechanical DCCB, as shown in Fig. 4. This topology takes advantage of discharging of the capacitor $C_{A}$ to recharge the 
pre-charged capacitor during reclosing operation.

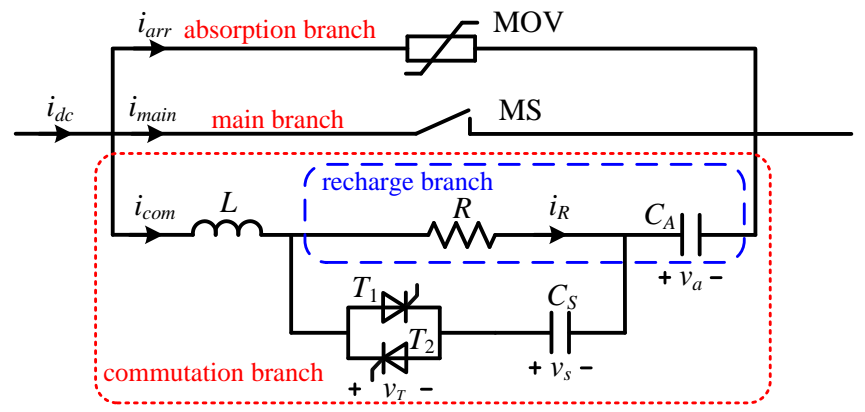

Fig. 4. Structure of the improved mechanical DC circuit breaker.

As can be seen, the improved DCCB also consists of three parallel branches, a main branch, a commutation branch, and an absorption branch. The main branch and absorption branch is similar to that of the coupling mechanical DCCB topology. The commutation branch adopts a recharge branch with a pre-charged capacitor $C_{S}$, an auxiliary capacitor $C_{A}$, an inductor $L$, and anti-parallel thyristors $T_{1}$ and $T_{2}$. The capacitor $C_{S}$ is precharged by a DC power supply.

In normal operation, the DC current $I_{d c}$ only flows through the main branch. The capacitor $C_{S}$ is precharged. On receiving a tripping order, the mechanical switch opens firstly and the arc is established between the contacts. After the contacts reaching sufficient dielectric distance, thyristors $T_{1}$ and $T_{2}$ are turned on. Then, an oscillation current is imposed on $i_{\text {main }}$ to extinguish the arc on the MS through the red line shown in Fig. 5(a). The arc is extinguished when $i_{\text {main }}$ reaches zero. To ensure reliable arc-extinguish, the thyristors remain turning on for several oscillation periods to generate multiple zero-crossing points. Subsequent to the delay of arc-extinguish time $\Delta t_{a e}$, the DC current $i_{\mathrm{dc}}$ will be diverted to the commutation branch. Then, the DC current charges the capacitors $C_{S}$ and $C_{A}$, as shown in Fig. 5(b). Once the sum of voltages of the capacitors reaches the threshold of MOVs, the DC current will be commutated to the absorption branch. Once $i_{a r r}$ is dissipated by the arresters, the DC fault current is completely cleared and the voltage across the breaker restores to $V_{d c}$. The first tripping operation finishes. 


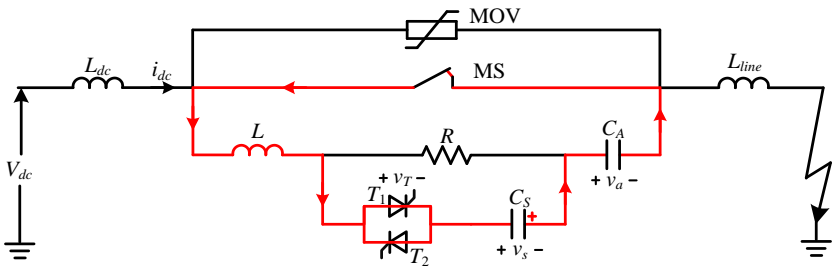

(a) process of arc-extinguish

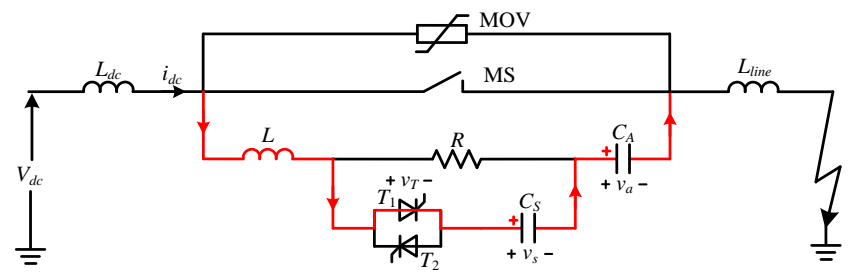

(b) process of commutation

Fig. 5. The first tripping operation of the proposed mechanical DCCB.

After deionization of faulty lines, the DCCB begins to automatically re-close. Since $C_{\mathrm{s}}$ is reversely charged by fault current during the first tripping, thyristor $T_{2}$ is turned on to discharge $C_{s}$ prior to re-closure of MS. After sufficient discharge time, MS re-closes. Then, $C_{S}$ will be recharged and $C_{A}$ will be discharged within hundreds of microseconds. The current path is shown in the red line of Fig. 6(a). Due to the unidirectional conductivity of thyristor $T_{2}, C_{s}$ is unable to discharge and its voltage will remain the pre-set value. As a result, it is able to generate an oscillation current again. Meanwhile, the residual voltage across $C_{A}$ discharges through the red line shown in Fig. 6(b), and eventually decays to $0 \mathrm{kV}$. If the DCCB re-closes to a permanent fault, $T_{1}$ and $T_{2}$ will be turned on and DCCB is able to trip again.

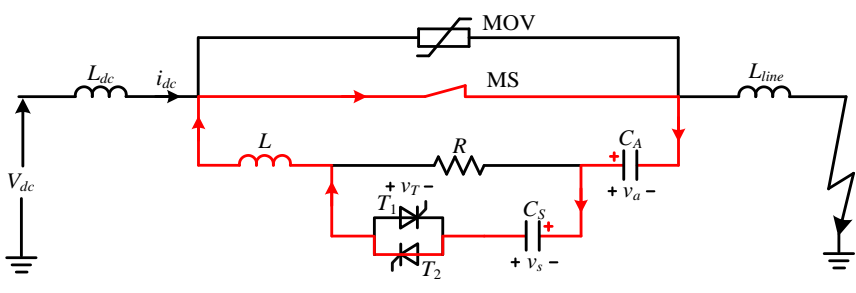

(a) process of $C_{S}$ recharge

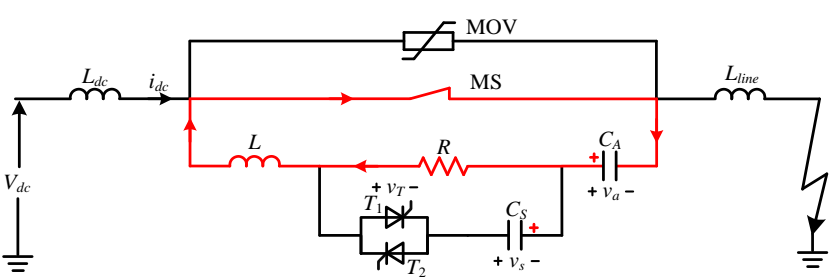

(b) process of $C_{A}$ discharge

Fig. 6. The reclosing operation of the proposed mechanical DCCB.

\section{Dynamic during First Tripping}

In normal operation, the DC current $i_{d c}$ only flows through the main branch. The voltage of the auxiliary capacitor $C_{A}\left(v_{a}\right)$ equals to 0 . The voltage of the capacitor $C_{S}\left(v_{s}\right)$ is pre-charged to $V_{\mathrm{s} 0}$.

On receiving the tripping order, MS opens firstly and then thyristor $T_{1}$ is turned on to extinguish the arc. During the short arc-extinguish time $\Delta t_{a e}$, as the current rise rate is limited by the current limiting inductance, the $i_{d c}$ is assumed to be constant. Therefore, we have

$$
i_{\text {main }}+i_{\text {com }}=I_{d c(t r i p)}
$$




$$
\begin{aligned}
L \frac{d i_{c o m}}{d t} & =v_{s}+v_{a}=V_{s 0}-\frac{1}{C_{\mathrm{S}}} \int_{0^{+}}^{t}\left(i_{c o m}-i_{R}\right) d t-\frac{1}{C_{\mathrm{A}}} \int_{0^{+}}^{t} i_{c o m} d t \\
& \approx V_{s 0}-\frac{1}{C_{\mathrm{S}}} \int_{0^{+}}^{t} i_{c o m} d t-\frac{1}{C_{\mathrm{A}}} \int_{0^{+}}^{t} i_{c o m} d t
\end{aligned}
$$

where $I_{d c(t r i p)}$ is the DC current at the moment when the thyristor $T_{1}$ is switched on, $i_{R}$ is the current flowing through the discharge resistor $R$. The integral of $i_{R}$ is far smaller than that of $i_{c o m}$ and therefore can be neglected. Assuming that $T_{1}$ receives a trigger signal at $\mathrm{t}=0$, from equation (2), the analytical expressions of $i_{\text {main }}, v_{s}$, and $v_{a}$ during arc-extinguished process are as follows

$$
\begin{gathered}
i_{\text {main }}=I_{d c(\text { trip })}+V_{s 0} \sin \left(\omega_{0} t\right) / Z_{c} \\
v_{s}=V_{s 0}-V_{s 0}\left[1-\cos \left(\omega_{0} t\right)\right] /\left(\omega_{0} Z_{c} C_{S}\right) \\
v_{a}=-V_{s 0}\left[1-\cos \left(\omega_{0} t\right)\right] /\left(\omega_{0} Z_{c} C_{A}\right)
\end{gathered}
$$

where $Z_{c}=\sqrt{L\left(C_{S}+C_{A}\right) /\left(C_{S} C_{A}\right)}, \omega_{0}=\sqrt{\left(C_{S}+C_{A}\right) /\left(L C_{S} C_{A}\right)}$.

After the delay of arc-extinguish time $\Delta t_{a e}$, the DC current is diverted to the commutation branch. Denote that at this instant the voltages of $C_{S}$ and $C_{A}$ are $V_{s 1}$ and $V_{a 1}$, respectively. Therefore, we have

$$
\begin{gathered}
i_{d c}=i_{c o m}=C_{S} \frac{d v_{s}}{d t}+i_{R} \approx C_{S} \frac{d v_{s}}{d t} \\
\left(L_{d c}+L\right) \frac{d i_{d c}}{d t}+\frac{1}{C_{A}} \int_{\Delta_{a c}^{+}}^{t} i_{d c} d t+v_{s}=V_{d c}-V_{a 1}
\end{gathered}
$$

The $i_{R}$ is far smaller than $i_{d c}$ and thus can be ignored. From equations (6) and (7), the analytical expressions of $i_{c o m}, v_{s}$, and $v_{a}$ during the commutating process are as follows:

$$
\begin{gathered}
i_{c o m}=I_{d c(t r i p)}+I_{0} \sin \left[\omega_{1}\left(t-\Delta t_{a e}\right)\right] \\
v_{s}=V_{s 1}+I_{0}\left[1-\cos \omega_{1}\left(t-\Delta t_{A E}\right)\right] /\left(\omega_{1} C_{S}\right)+I_{d c t r i p}\left(t-\Delta t_{a e}\right) / C_{S} \\
v_{a}=V_{a 1}+I_{0}\left[1-\cos \omega_{1}\left(t-\Delta t_{A E}\right)\right] /\left(\omega_{1} C_{A}\right)+I_{d c t r i p}\left(t-\Delta t_{a e}\right) / C_{A}
\end{gathered}
$$

where $Z_{c 1}=\sqrt{\left(L+L_{d c}\right)\left(C_{S}+C_{A}\right) /\left(C_{S} C_{A}\right)}, I_{0}=\left(V_{d c}-V_{s 1}-V_{a 1}\right) / Z_{c 1}, \omega_{1}=\sqrt{\left(C_{S}+C_{A}\right) /\left[\left(L+L_{d c}\right) C_{S} C_{A}\right]}$. Once the sum of voltages across the capacitors reaches the action threshold of MOVs, the commutation process ends.

\section{Dynamic during Reclosing}

Thyristor $T_{2}$ is firstly turned on and then MS re-closes. The main branch and commutation branch form an 
oscillating circuit. Therefore, we have

$$
L \frac{d i_{c o m}}{d t}+\frac{1}{C_{\mathrm{S}}} \int_{0^{+}}^{t} i_{c o m} d t+\frac{1}{C_{\mathrm{A}}} \int_{0^{+}}^{t} i_{c o m} d t=-V_{\mathrm{dc}}
$$

Assuming that MS re-closes at $\mathrm{t}=0$, from equation (11), the analytical expressions of $i_{c o m}, v_{s}$, and $v_{a}$ during the recharging process are as follows

$$
\begin{gathered}
i_{c o m}=-V_{d c} \sin \left(\omega_{0} t\right) / Z_{c} \\
v_{s}=-V_{d c}\left[1-\cos \left(\omega_{0} t\right)\right] /\left(\omega_{0} Z_{c} C_{S}\right) \\
v_{a}=V_{d c}-V_{d c}\left[\cos \left(\omega_{0} t\right)-1\right] /\left(\omega_{0} Z_{c} C_{A}\right)
\end{gathered}
$$

After recharge time of $\Delta t_{r c h}$, the oscillation ends with the arrival of zero current, due to the unidirectional conductivity of the thyristor $T_{2}$. The voltages of $C_{S}$ and $C_{A}$ are as follows

$$
\begin{gathered}
V_{s 2}=-2 V_{d c} /\left(\omega_{0} Z_{c} C_{S}\right) \\
V_{a 2}=V_{d c}-2 V_{d c} /\left(\omega_{0} Z_{c} C_{A}\right)
\end{gathered}
$$

$C_{S}$ is unable to discharge and its voltage will remain $V_{s 2}$, whereas the residual voltage across $C_{A}$ discharges through the red line shown in Fig. 6(a). The discharge process of $C_{A}$ is described by

$$
L \frac{d i_{c o m}}{d t}+\frac{1}{C_{\mathrm{A}}} \int_{\Delta t_{r c h}}^{t} i_{c o m} d t+R i_{c o m}=-V_{a 2}
$$

Since the discharge resistor $R$ is relatively large, the discharge process is an overdamped process. Therefore, the analytical expressions of $v_{a}$ during the discharge process is as follows

$$
v_{a}=\frac{V_{a 2}}{2 \beta}\left[(\alpha+\beta) e^{(-\alpha+\beta) t}-(\alpha-\beta) e^{-(\alpha+\beta) t}\right]
$$

where $\alpha=R /(2 L), \beta=\sqrt{\alpha^{2}-1 /(L C)}$. After the sufficient decay time, which equals $5 /(\alpha-\beta), v_{a}$ almost decays to 0 .

\section{Parameter Design of the Proposed Mechanical DCCB}

\section{A. Dimensioning of the Pre-Charged Voltage $V_{s 0}$}

During the tripping process, capacitor $C_{S}$ will discharge to impose an inverse oscillation current on the main branch current to extinguish the arc. The amplitude of the oscillation current represents the maximum 
current that the DCCB can interrupt successfully (maximum breaking current). From equation (3), it is evident that the maximum breaking current is related to the pre-charged capacitor voltage $\left(V_{s}\right)$. According to the positive direction of $v_{s}$ shown in Fig. 4, the value $V_{s 0}$ is negative. Fig. 7 shows the absolute value of $V_{s 0}$ versus the maximum breaking current of DCCB. Parameters for the tested mechanical DCCB are listed in Table II, except that $\left|V_{s 0}\right|$ is varied from 0 to $500 \mathrm{kV}$. The representative DC grid requires that the DCCB is able to interrupt the fault current of $25 \mathrm{kA}$. To achieve the maximum breaking current of $25 \mathrm{kA},\left|V_{s 0}\right|$ should not be less than $314 \mathrm{kV}$. As a conservative design, the pre-charged voltage $V_{s 0}$ is dimensioned as $-320 \mathrm{kV}$.

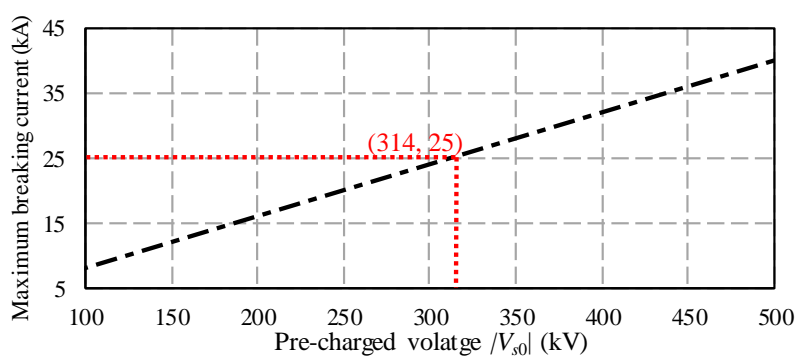

Fig. 7. Maximum breaking current versus pre-charged voltage $\left|V_{s 0}\right|$.

\section{B. Dimensioning of the Inductance $L$}

From equation (3), the arc on the MS is commonly extinguished before the oscillation current reaches the first peak point. Thus, the arc-extinguished time $\Delta t_{a e}$ is normally less than a quarter of the oscillation period. Conservatively, $\Delta t_{a e}$ takes its theoretical maximum.

Fig. 8 shows the arc-extinguish time of DCCB versus inductance $L$. Decreasing inductance $L$ results in reduced $\Delta t_{a e}$, which represents a higher interruption speed of DCCB. However, a low inductance means higher current change rate $(\mathrm{d} I / \mathrm{d} t)$, which leads to lower reliability and higher cost of the thyristors and MS. There is a trade-off between the arc-extinguish time and the cost for the dimension of the inductance. In this paper, the inductance is designed as $0.8 \mathrm{mH}$ to achieve the arc-extinguish time of $100 \mu \mathrm{s}$.

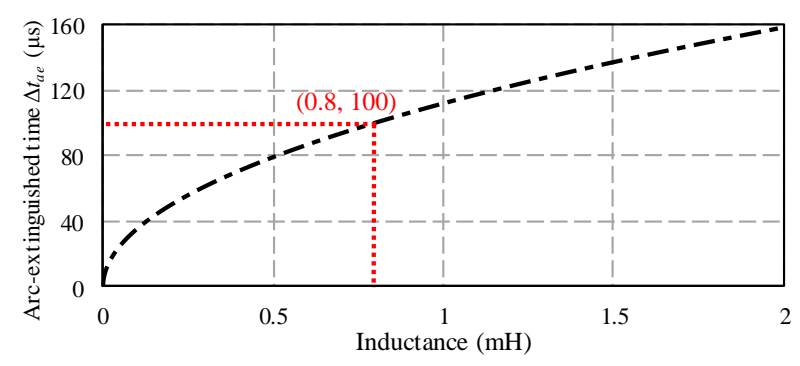


Fig. 8. Arc-extinguish time $\Delta t_{a e}$ versus inductance $L$.

\section{Dimensioning of the Capacitances}

After the arc is extinguished, the residual current is continually flowing through the commutation branch and charges the capacitors until the sum of their voltages reaches the thresholds of the arrester. The duration of this commutation process $\left(\Delta t_{c o m}\right)$ can be calculated from equations (9)-(10). To simplify the calculation, the DC current is assumed to be constant and equals to $I_{d c}(t r i p)$. Therefore, $\Delta t_{c o m}$ is obtained

$$
\Delta t_{c o m}=\frac{C_{E}}{I_{d c(t r i p)}}\left(V_{a r r}+V_{s 0} \cos \Delta t_{A E}\right)
$$

where $C_{E}=C_{S} C_{A} /\left(C_{S}+C_{A}\right), V_{a r r}$ represents the protection threshold of the arrester.

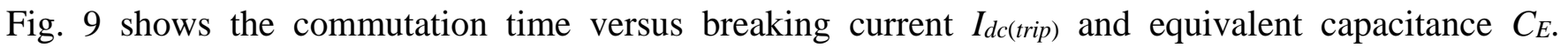
Increasing the breaking current $I_{d c(t r i p)}$ or decreasing the equivalent capacitance $C_{E}$ results in reduced commutation time. There is a trade-off between the commutation time and the cost for the dimension of the capacitors. The equivalent capacitance is designed as $5.1 \mu \mathrm{F}$ to achieve the commutation time of $0.5 \mathrm{~ms}$ in terms of $I_{d c(t r i p)}=10 \mathrm{kA}$. The commutation time versus breaking current with $C_{E}=5.1 \mu \mathrm{F}$ is shown in Fig. 10.

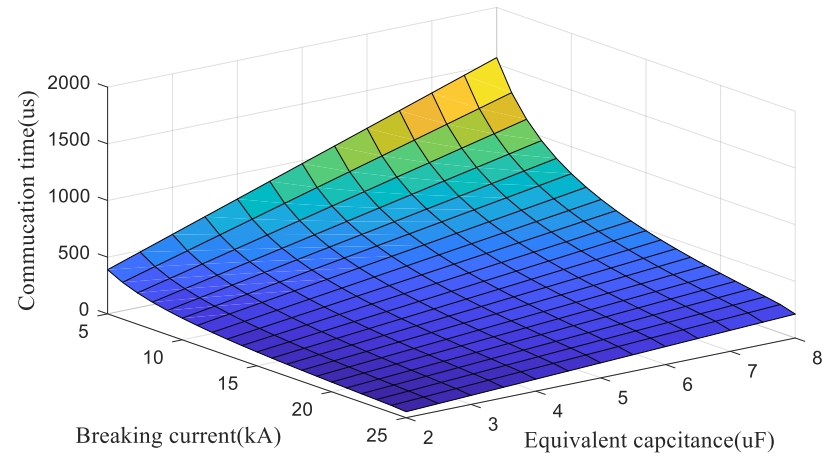

Fig. 9. Commutation time versus breaking current $I_{d c(t r i p)}$ and equivalent capacitance $C_{E}$.

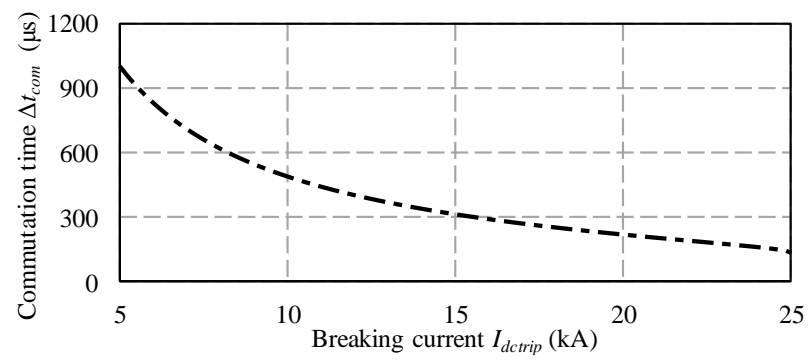


Fig. 10. Commutation time versus breaking current with $C_{E}=5.1 \mu \mathrm{F}$.

During reclosing, $C_{S}$ is recharged while the auxiliary capacitor $C_{A}$ is discharged. The relationship between the recharged voltage $V_{s 2}$ and the capacitance ratio $C_{S} / C_{A}$ can be obtained from equation (15).

Fig. 11 shows the recharged voltage $\left|V_{s 2}\right|$ versus capacitance ratio $C_{S} / C_{A}$. To achieve a recharged voltage of $-320 \mathrm{kV}$, the capacitance ratio needs to be less than 2.125 . As a conservative design, the capacitance ratio $C_{S} / C_{A}$ is dimensioned as 2.04. Combined with $C_{E}=5.1 \mu \mathrm{F}$, the capacitance of the $C_{S}$ and $C_{A}$ are chosen as $15.5 \mu \mathrm{F}$ and $7.6 \mu \mathrm{F}$, respectively.

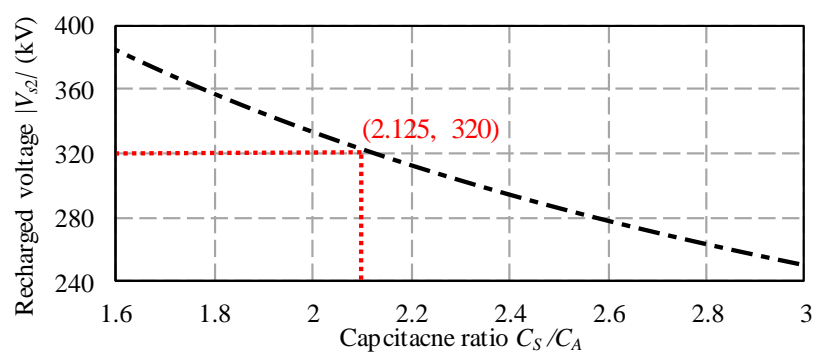

Fig. 11. Recharged voltage $\left|V_{s 2}\right|$ versus capacitance ratio.

\section{Dimensioning of the Discharge Resistance $R$}

Following the recharge process, the voltage across $C_{A}$ reaches a steady-state value. Then, through the circuit composed of discharge resistor, $C_{A}$ discharges and its voltage eventually decays to 0 , as shown in equation (18). The decay time of this voltage is related to the value of discharge resistance.

Fig. 12 shows the decay time versus the discharge resistance. The residual voltage of $v_{a}$ may affect the arcextinguish process of the second trip. To ensure the twice-tripping capability of the DCCB, the voltage across $C_{A}$ must decrease to 0 prior to the second breaking. Considering the secondary interruption normally starts at $5 \mathrm{~ms}$ subsequent to re-closure, the decay time should be no more than this duration. Therefore, the value of discharge resistance is dimensioned as $125 \Omega$.

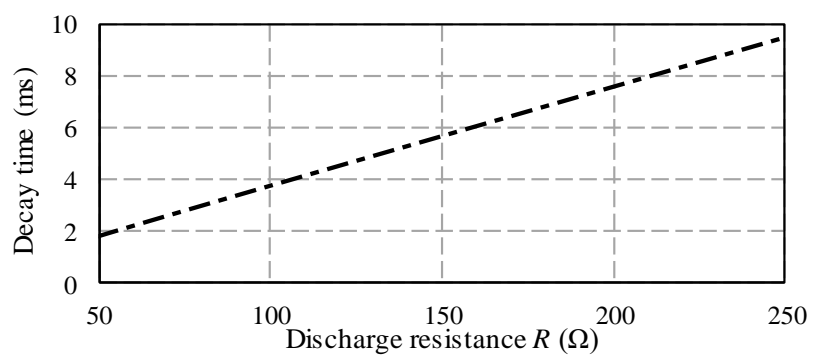


Fig. 12. Decay time versus discharge resistance.

\section{E. Dimensioning of the Rating of Thyristors}

To achieve the control of oscillation current, the inverse paralleled thyristors are implemented in the commutation branch, as shown in Fig. 4.

During normal operation, there is no current flowing through the commutation branch. The thyristors directly withstand the voltage stress across the capacitor $C_{S}$. Therefore, the voltage rating of the thyristors is $V_{s 0}$.

During reclosing operation, the oscillation current, caused by the discharge of the $C_{A}$, flows through the thyristors to recharge the $C_{S}$. From equation (12), the maximum current through the thyristors is

$$
I_{T}=V_{d c} / Z_{c}
$$

Besides, the thyristor $T_{2}$ is turned off after the capacitor $C_{s}$ has been recharged. The thyristors $T_{1}$ and $T_{2}$ need temporarily withstand the DC line voltage $\left(V_{s 2}+V_{a 2}=V_{d c}\right)$.

Take ABB's Thyristor 5STP 08F6500 [30] as example to design $T_{1}$ and $T_{2}$. This type of thyristor has a rated voltage of $4.34 \mathrm{kV}$ and can withstand the peak voltage of $6.5 \mathrm{kV}$ for $10 \mathrm{~ms}$. And it can tolerate the surge current of $15.1 \mathrm{kA}$. Therefore, it is required to combine 3 individual thyristors in parallel (withstand $45.3 \mathrm{kA}$ ) as a group and connect 80 groups in series (withstand $520 \mathrm{kV}$ ) to form $T_{1}$ or $T_{2}$.

\section{Simulation of the Proposed Mechanical dCCB}

To verify the performance of the mechanical DCCB, the test system shown in Fig. 13 is simulated. In Fig. 13 , the DCCB is connected to a stiff $500 \mathrm{kV}$ DC voltage source. The nominal DC current is $3.0 \mathrm{kA}$. The switch $S_{f t t}$ is closed to initiate the fault. Such stiff DC voltage source imposes most stringent requirements on DCCB.

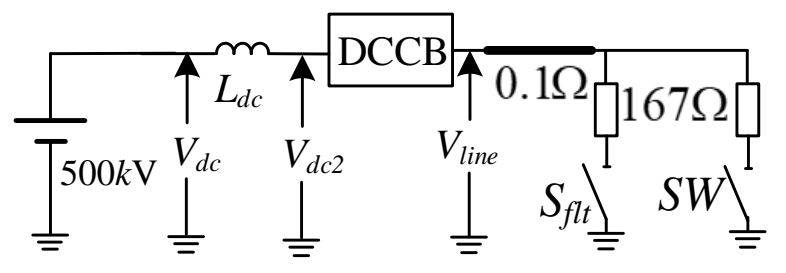

Fig. 13. Tested single-terminal system. 
Table II Parameters of the Tested Mechanical DCCB

\begin{tabular}{ll}
\hline Parameter & Value \\
\hline Rate DC voltage $V_{d c n} / \mathrm{kV}$ & 500 \\
Rate DC current $I_{d c n} / \mathrm{kA}$ & 3 \\
Maximum breaking current $I_{\text {max }} / \mathrm{kA}$ & 25 \\
Operation time of the MS $T_{\text {mec }} / \mathrm{ms}$ & 2.5 \\
Pre-charged voltage $V_{s 0}$ of capacitor $C_{S} / \mathrm{kV}$ & -320 \\
Pre-charged capacitance $C_{S} / \mu \mathrm{F}$ & 15.5 \\
Auxiliary capacitance $C_{A} / \mu \mathrm{F}$ & 7.6 \\
Oscillation inductance $L / \mathrm{mH}$ & 0.8 \\
Discharge resistance $R / \Omega$ & 125 \\
Rated voltage of the thyristor valve $V_{T n} / \mathrm{kV}$ & 320 \\
Rated voltage of the arrester $V_{a r r} / \mathrm{kV}$ & 660 \\
\hline
\end{tabular}

Table II lists the parameters of the tested mechanical DCCB. Sflt is closed at $1 \mathrm{~s}$ to simulate a permanent low-resistance fault. The tripping order of the DCCB is sent at $1.003 \mathrm{~s}$ to simulate the fault detection delay. Due to $2.5 \mathrm{~ms}$ of the operation delay of MS, the trigger signals of thyristors $T_{1}$ and $T_{2}$ are sent at $1.0055 \mathrm{~s}$ and last until $1.007 \mathrm{~s}$. The deionization time is set as $300 \mathrm{~ms}$. Therefore, the trigger signal of thyristor $T_{2}$ is issued at $1.293 \mathrm{~s}$, and MS is re-closed at $1.303 \mathrm{~s}$. Then, the protection system determines whether the fault is still existing. Once the DC current exceeds $6.8 \mathrm{kA}$, tripping order of DCCB will be sent again. The simulation results are shown in Fig. 14 and Fig. 15.

Fig. 14 (a) shows the currents $i_{m a i n}, i_{c o m}$, and $i_{a r r}$. Once the thyristors receive the trigger signal, $i_{m a i n}$ begins to decrease and reaches zero after $\Delta t_{a e}$ arc-extinguish time. Then, the DC current transfers to the commutation branch and charges $C_{S}$ and $C_{A}$. During the commutation time of $\Delta t_{c o m}$, the current in the commutation branch $i_{c o m}$ barely changes. The $\Delta t_{c o m}$ is approximately $600 \mu \mathrm{s}$ and the tripping current $I_{d c(t r i p)}$ is $8 \mathrm{kA}$, which is in line with the calculated value shown in Fig. 10. In the meantime, the voltages across capacitors $C_{A}$ and $C_{S}$ ( $v_{a}$ and $v_{s}$ ) increase with a fast slope, as shown in Fig. 14 (b). Once the sum of $v_{a}$ and $v_{s}$ reaches the threshold (typically $1.5 V_{\mathrm{dcn}}$ ) of the arresters banks, the arresters conduct to suppress the current, and the DC current gradually decreases to zero. After $i_{\text {arr }}$ decreasing to zero, $C_{A}$ discharges through the commutation branch, and its voltage, which equals the voltage across the breaker, resumes to $V_{d c}$.

Fig. 14 (b) shows the voltage in the mechanical DCCB during fault clearance. Upon receiving the tripping 
signal, the voltage across thyristors $v_{T}$ decreases to almost zero immediately. Upon receiving the tripping signal, the voltage across thyristors $v_{T}$ decreases to zero immediately. Then, $v_{a}$ and $v_{s}$ increase during the time of $\Delta t_{a e}$ and $\Delta t_{c o m}$. Once arresters conduct, $v_{a}$ and $v_{T}$ remain constant since the thyristors are turned off. Before $i_{\text {arr }}$ decreases to zero, $v_{a}$ is maintained at the range from $720 \mathrm{kV}$ to $660 \mathrm{kV}$.

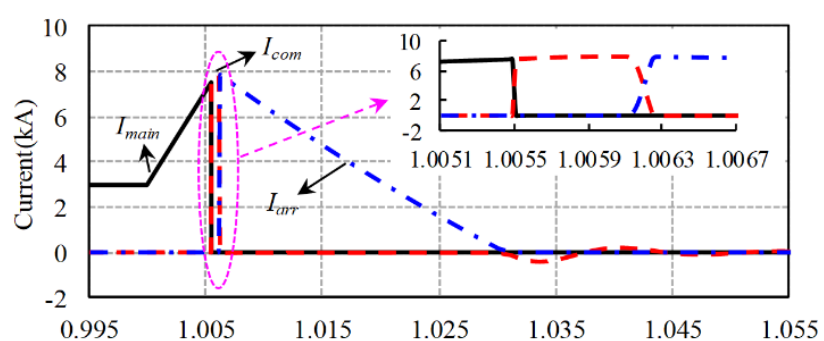

(a) Currents in the DCCB during fault clearance

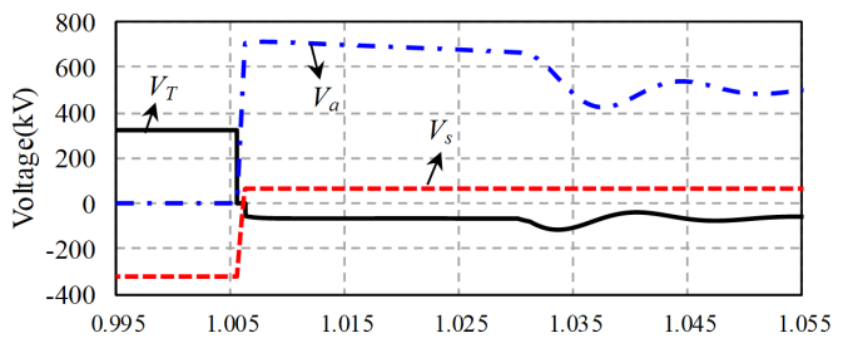

(b) Voltages of the DCCB during fault clearance

Fig. 14. Simulation of the fault clearance of the mechanical DCCB.

Fig. 15 shows the voltages and currents of the mechanical DCCB during reclosing. Prior to re-closure of MS, $v_{s}$ discharges to zero by turning on $T_{2}$. Once MS re-closes, $v_{s}$ is recharged and $v_{a}$ is discharged. The recharge process completes within $200 \mu \mathrm{s}$. Finally, $v_{s}$ restores to $-320 \mathrm{kV}$ and $v_{a}$ decreases to $-176 \mathrm{kV}$, as shown in Fig. 15 (a). Therefore, the capacitor $C_{S}$ is able to generate an oscillation current again. Then, $C_{A}$ will discharge through the discharge resistor $R$ and its voltage decreases to 0 within $5 \mathrm{~ms}$. The mechanical DCCB recovers to the initial state before tripping operation and regains the interruption capability. As shown in Fig. 15(b), once the DCCB re-closes, the oscillation circuit generates an impulse current with $40.56 \mathrm{kA}$ peak value. The second tripping operation is similar to that as shown in Fig. 14(a).

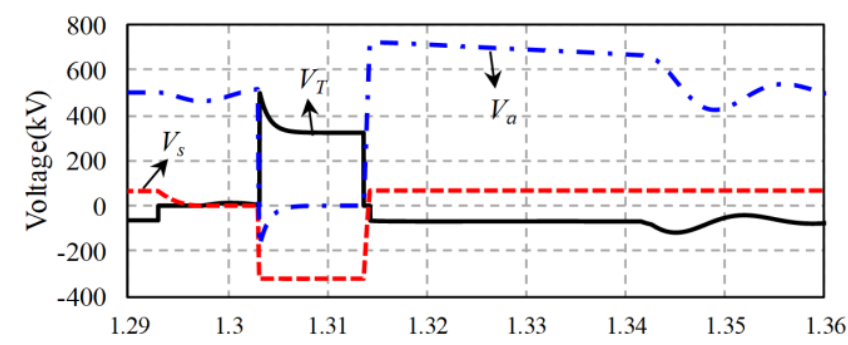

(a) Voltages of the DCCB during reclosing

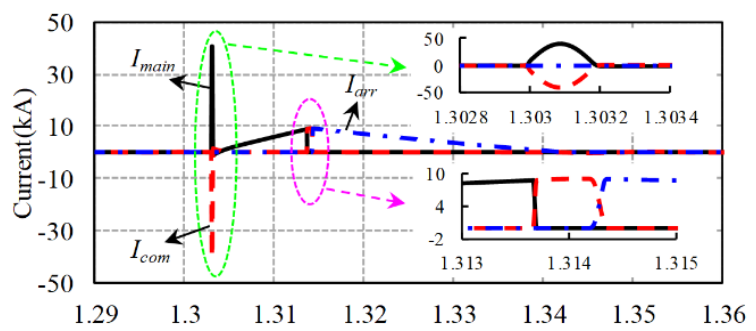

(b) Currents in the DCCB during reclosing

Fig. 15. Simulation of reclosing of the mechanical DCCB.

\section{Performance of The DC Grid Embedding the Mechanical DCCB}

To verify the applicability of the improved mechanical DCCB, a further simulation is performed in a four- 
terminal HVDC grid embedding this DCCB, as shown in Fig. 1. The main circuit parameters of the converters in this system are given in Table III. The overhead lines are modeled with the frequency-dependent phase model provided by PSCAD/EMTDC. The parameters of transmission lines are shown in Table IV.

TABLE III PARAMETERS OF THE CONVERTER STATIONS

\begin{tabular}{ccccc}
\hline Parameters & MMC1 & MMC2 & MMC3 & MMC4 \\
\hline DC voltage rating (kV) & \pm 500 & \pm 500 & \pm 500 & \pm 500 \\
Power rating (MVA) & 3000 & 1500 & 1500 & 3000 \\
AC voltage (kV) & 230 & 230 & 525 & 525 \\
Control mode & $V_{a c}-f$ & $V_{a c}-f$ & $P-Q$ & $V_{d c}-Q$ \\
Submodule capacitance $(\mathrm{mF})$ & 15 & 8 & 8 & 15 \\
Arm inductance $(\mathrm{mH})$ & 50 & 100 & 100 & 50 \\
Submodule number & 244 & 244 & 244 & 244 \\
Polar DC inductance $(\mathrm{mH})$ & 150 & 150 & 150 & 150 \\
Neutral DC inductance $(\mathrm{mH})$ & 300 & 300 & 300 & 300 \\
Grounding pole resistance $(\Omega)$ & None & None & None & 15 \\
\hline
\end{tabular}

TABLE IV PARAMETERS OF THE OVERHEAD TRANSMISSION LINE

\begin{tabular}{ccccc}
\hline Parameters & Line1 & Line2 & Line3 & Line4 \\
\hline Overhead line length $(\mathrm{km})$ & 49.6 & 205.1 & 187.1 & 206.4 \\
Overhead line resistance $(\mathrm{m} \Omega / \mathrm{km})$ & 9.96 & 9.96 & 9.96 & 9.96 \\
Metallic return resistance $(\mathrm{m} \Omega / \mathrm{km})$ & 18.8 & 18.8 & 18.8 & 18.8 \\
\hline
\end{tabular}

MMC1 and MMC2 operate as inverters in AC voltage and frequency control mode to maintain the stability of the wind farm. MMC3 operates as a rectifier in active and reactive power control mode. MMC4 operates as a rectifier in DC voltage control mode. Besides, the system also adopts a centralized protection scheme that the central controller detects the faults and delivers the trip orders to the specified DCCBs. The relay time of the DCCBs is assumed as $3 \mathrm{~ms}$.

\section{A. Response to Permanent DC Fault}

To verify the interruption capability of the mechanical DCCB in a four-terminal HVDC grid, a permanent pole-to-pole DC fault is applied at Flt1 at $2.0 \mathrm{~s}$. The fault location is at the DC terminal of MMC1, as shown in Fig. 1. The DCCBs receive the tripping order at $2.003 \mathrm{~s}$. The reclosing time is set at $2.303 \mathrm{~s}$ due to $300 \mathrm{~ms}$ of the deionization time. 


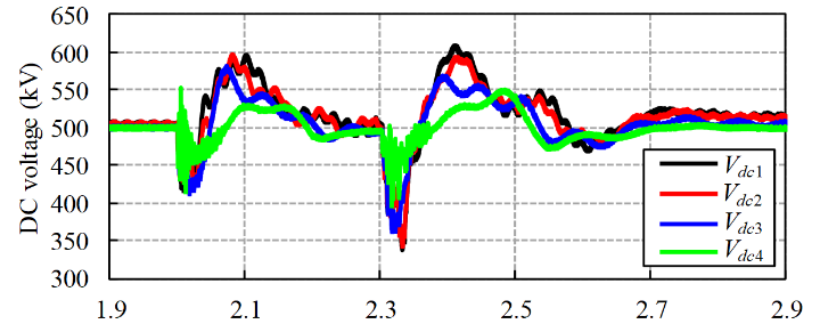

(a) DC voltage of positive pole at the DC terminal of each converter

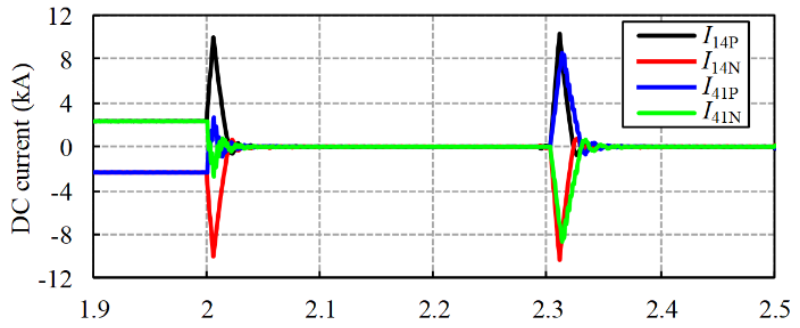

(b) DC current in the faulty transmission line

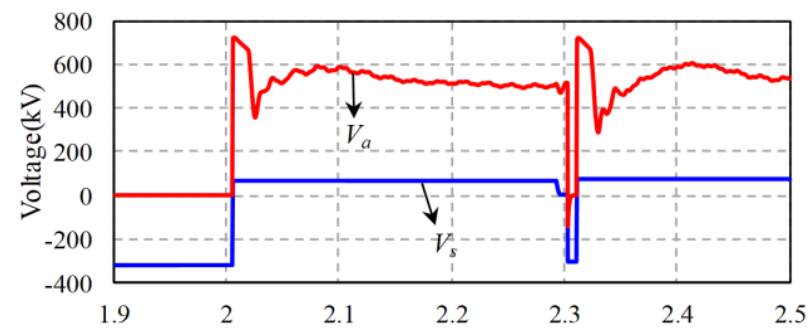

(c) Capacitor voltages in CB14P

Fig. 16. DC grid response to a pole-to-pole DC fault.

Fig. 16 (a) shows the DC bus voltages of MMC1-MMC4. When the fault occurs, all DC voltages rapidly decrease. After fault clearance, all DC voltages restore to normal value after a certain transient. When the breakers re-close, the DC voltages $V_{d c 1}, V_{d c 2}$, and $V_{d c 3}$ decrease to $350 \mathrm{kV}$, while $V_{d c 1}$ decreases to $400 \mathrm{kV}$. Then, the DC voltages are similar to their performance during the first tripping.

Fig. 16 (b) shows the DC currents in the faulty transmission line during the operation of the DCCBs. When a fault occurs or DCCBs re-close, the DC current rises rapidly. During the first tripping, $I_{14 P}$ reaches the peak value of $10.01 \mathrm{kA}$ at $2.0059 \mathrm{~s}$, and $I_{41 P}$ reaches the peak value of $2.69 \mathrm{kV}$ at $2.0064 \mathrm{~s}$. During the second tripping, $I_{14 P}$ reaches the peak value of $10.34 \mathrm{kA}$ at $2.3111 \mathrm{~s}$, and $I_{41 P}$ reaches the peak value of $8.60 \mathrm{kA}$ at $2.3132 \mathrm{~s}$.

Fig. 16 (c) shows the voltages across capacitors in CB14P. Prior to reclosing operation, $C_{S}$ is completely discharged and its voltage $v_{s}$ decreases to 0 at $2.296 \mathrm{~s}$. After the breakers re-close at $2.303 \mathrm{~s}, v_{s}$ is recharged to $-304.67 \mathrm{kV}$ immediately, while $v_{a}$ reaches $142.24 \mathrm{kV}$ and then is discharged to 0 at $2.308 \mathrm{~s}$. That ensures the second interruption capability of the mechanical DCCB.

Table V shows the performance of the DCCBs on the faulty line. According to the values shown in Table $\mathrm{V}$, the designed energy absorption of the arrester would not be less than $80.81 \mathrm{MJ}(42.33+38.48 \mathrm{MJ})$. Besides, 
during reclosing, the energy absorbed by CB41P and CB41N is larger than that of the CB14P and CB14N, though CB14P and CB14N have a larger peak fault current. It proves that the energy absorption of the arrester is mainly concerned with the energy stored in the transmission line, rather than the peak fault current.

TABLE V PERFORMANCE OF THE DCCBS ON THE FAULT LiNE

\begin{tabular}{ccccc}
\hline Parameters & CB14P & CB14N & CB41P & CB41N \\
\hline Peak fault current during first tripping (kA) & 10.01 & 10.02 & 2.69 & 2.72 \\
Energy absorption first tripping (MJ) & 42.33 & 42.39 & 2.82 & 2.72 \\
Peak fault current during second tripping (kA) & 10.34 & 10.34 & 8.60 & 8.67 \\
Energy absorption during second tripping (MJ) & 38.48 & 38.42 & 48.13 & 48.19 \\
\hline
\end{tabular}

\section{B. Impact of the Dispersivity of the Breaking Time}

Due to the time dispersivity of the mechanical movement of contacts during the tripping process of mechanical DCCBs, the breakers at positive and negative poles may not operate at the same time. Therefore, it is necessary to study the operational dispersivity of the two DCCBs and its influence on the performance of DCCBs.

A permanent pole-to-pole fault is applied at Flt1 at $2.0 \mathrm{~s}$. To simulate the time dispersivity of the breaking time, assume the breaking time of CB14P and CB14N are $T_{b}$ and $T_{b}+\Delta t$, respectively. $\Delta t$ is the dispersion time in the range from 0 to $0.5 \mathrm{~ms}$. The simulation results are shown in Table VI.

Table VI shows the performance of the breakers under different dispersion time. The dispersion time mainly influences the peak fault current of CB14N and energy absorption of CB14P. These parameters increase with the rise of dispersion time. Therefore, the influence of the dispersivity of the breaking time should be considered in the design of the energy absorption of DCCB.

TABLE VI IMPACT OF THE INTERRUPTING TIME DISPERSION ON PERFORMANCE OF BREAKERS

\begin{tabular}{cccccc}
\hline$\Delta t(\mathrm{~ms})$ & 0.1 & 0.2 & 0.3 & 0.4 & 0.5 \\
\hline Peak fault current of CB14P (kA) & 10.02 & 10.02 & 10.01 & 10.01 & 10.01 \\
Peak fault current of CB14N (kA) & 10.17 & 10.31 & 10.44 & 10.56 & 10.67 \\
Energy absorption of CB14P (MJ) & 42.96 & 43.60 & 44.23 & 44.88 & 45.52 \\
Energy absorption of CB14N (MJ) & 42.61 & 42.81 & 42.99 & 43.14 & 43.29 \\
\hline
\end{tabular}

\section{Response to Malfunction of a DCCB}


In the case of a DCCB malfunction, the normally operating DCCB will bear the fault current and pole-topole voltage until the backup protection reacts. It is an extremely severe situation for the normal operating DCCB. Therefore, this situation should also be considered in the design of DCCB.

A permanent pole-to-pole fault is applied at Flt1 at $2.0 \mathrm{~s}$ to simulate this situation. Assume that CB14P can operate normally and $\mathrm{CB} 14 \mathrm{~N}$ fails to complete the tripping operation. After receiving the abnormally signal sent by $\mathrm{CB} 14 \mathrm{~N}$, the backup protection commands $\mathrm{CB} 12 \mathrm{~N}$ to trip at $2.007 \mathrm{~s}$. Then, the negative pole of MMC1 begins to block at $2.0071 \mathrm{~s}$ (considering the signal process delay), and the associated AC breakers completely trip at 2.009 s. The simulation results are shown in Fig. 17.

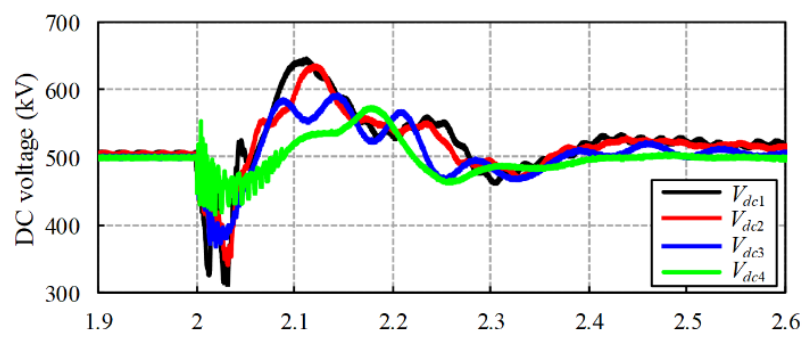

(a) DC voltages of positive pole at the DC terminal of each

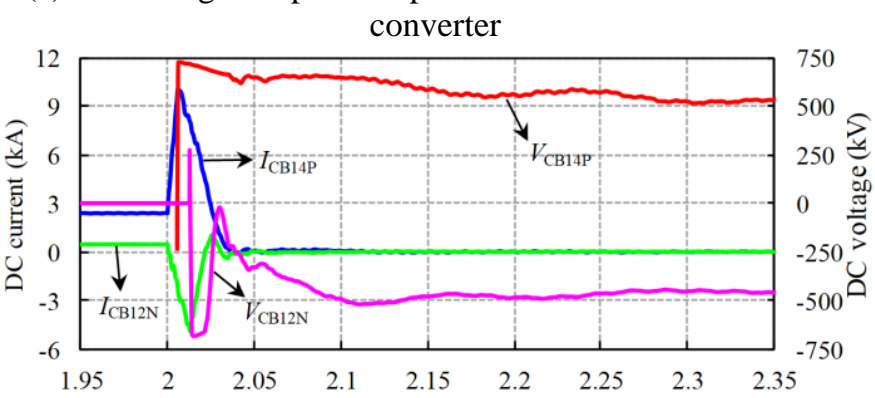

(c) Transient performance of CB14P and CB12N

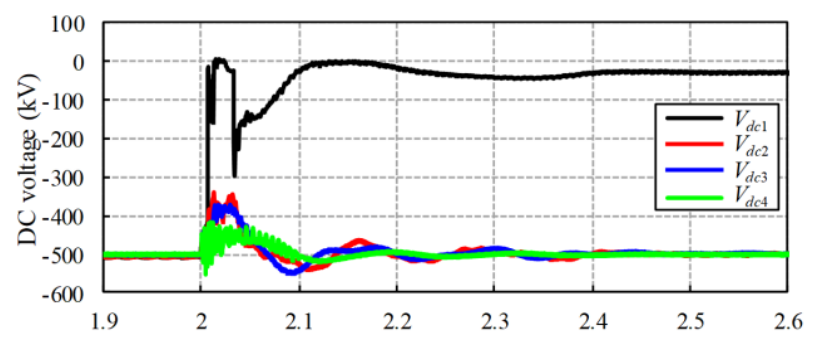

(b) DC voltages of negative pole at the DC terminal of each converter

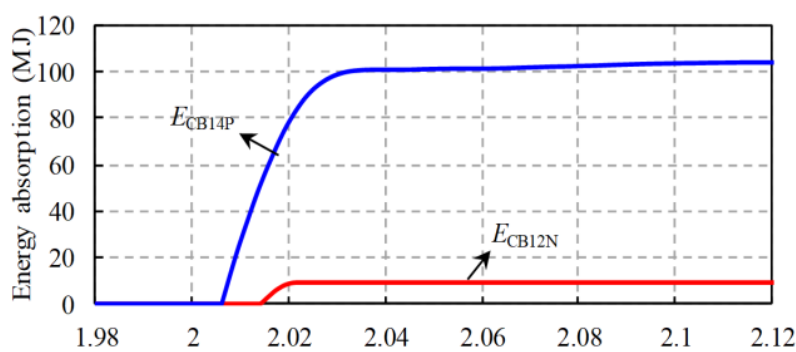

(d) Energy absorption of CB14P and CB12N

Fig. 17. Response to a pole-to-pole DC fault with a negative DCCB failure.

Fig. 17 (a) and (b) show the DC bus voltages of the positive and negative poles, respectively. Similar to that in Fig. 16 (a), the bus voltages of positive pole recover to $500 \mathrm{kV}$ after fault clearance, due to the normal operation of CB14P. As shown in Fig. 17 (b), the bus voltages of the negative pole of each converter can also restore to $500 \mathrm{kV}$ except that of MMC1. The negative voltage of MMC1 increases to 0 rapidly after blocked. Then, it decreases to $-300 \mathrm{kV}$ after AC breakers tripping. Finally, the negative voltage of MMC1 becomes stable at the level of $30 \mathrm{kV}$.

Fig. 17 (c) shows the transient performance of the tripping breakers CB14P and CB12N. The fault current 
of $\mathrm{CB} 14 \mathrm{P}$ reaches the peak value of $10.03 \mathrm{kA}$ at $2.006 \mathrm{~s}$, and then the voltages across CB14P reached the peak voltage of $726.12 \mathrm{kV}$ at $2.007 \mathrm{~s}$. Afterward, the fault current of CB12N reaches the peak value of 4.89 $\mathrm{kA}$ at $2.013 \mathrm{~s}$, and then voltages across $\mathrm{CN} 12 \mathrm{~N}$ reaches the peak voltage of $683.84 \mathrm{kV}$ at $2.015 \mathrm{~s}$. Besides, due to no operation of CB14N, the arrester in CP14P needs to bear the pole-to-pole voltage after CP14P trips. Thus, the arrester of CB14P conducts continuously until current on $\mathrm{CB} 12 \mathrm{~N}$ reached 0.

Fig. 17 (d) shows the energy absorption of CB14P and CB12N. Due to the earlier operating of CB14P, the energy absorption of CB14P rises earlier than that of CB12N. The eventual energy absorption of CB14P and CB12N are 103.91 MJ and 9.18 MJ, respectively. Therefore, the designed energy absorption of the arrester would not be less than 103.91 MJ.

\section{Response to Malfunctions of Both DCCBs}

A permanent pole-to-pole fault is applied at Flt1 at $2.0 \mathrm{~s}$. Assume that both CB14P and CB14N cannot operate normally. The backup protection commands CB12P and CB12N to trip at $2.007 \mathrm{~s}$. Then, both positive and negative poles of MMC1 begin to block at $2.0071 \mathrm{~s}$ and the associated AC breakers completely trip at 2.009 s. The simulation results are shown in Fig. 18.

Fig. 18 (a) shows the DC bus voltages of the positive pole of MMC1-MMC4. The DC bus voltages of each converter can restore to $500 \mathrm{kV}$ except that of MMC1. The voltage of MMC1 decreases to 0 rapidly after being blocked.

Fig. 18 (b) shows the current of MMC1 and adjacent lines. $I_{L 12 \mathrm{P}}$ is successfully interrupted by CB12P, and it reaches the peak fault current of $6.64 \mathrm{kA}$ at $2.013 \mathrm{~s}$. Due to the operation of CB12P, $I_{L 14 \mathrm{P}}$ begins to decrease after reaching the peak value of $14.20 \mathrm{kA}$ at $2.013 \mathrm{~s}$. Besides, because the energy stored in the current limiting inductor and neutral reactor of $\mathrm{MMC} 1$ cannot be dissipated through the arrester of $\mathrm{CB} 12 \mathrm{P}, I_{L 14 \mathrm{P}}$ and $I_{\mathrm{MMC} 1}$ need relatively long time to dissipate to 0 through the stray circuit. 


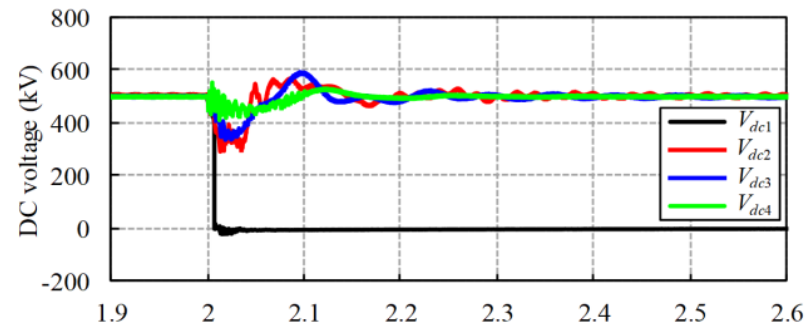

(a) DC voltages of positive pole at the DC terminal of each converter

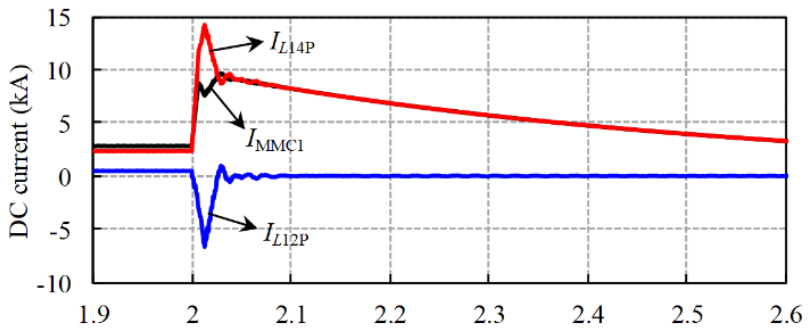

(b) DC currents of positive pole of MMC1 and its connected lines

Fig. 18. Response to a pole-to-pole DC fault with both DCCBs failure.

\section{CONCLUSION}

This paper proposes a novel mechanical DCCB with the twice-interruption capability to meet the requirement of overhead DC grid for automatic re-closure. This DCCB takes advantages of the discharging process of capacitor $C_{A}$ to recharge capacitor $C_{S}$ and thus achieve the second interruption capability. Taking the requirements of the representative four-terminal DC grid as an example, the parameter design methods of this DCCB are proposed. The DCCBs are designed as $-320 \mathrm{kV}$ pre-charged voltage of $v_{\mathrm{s}}, C_{S}$ of $15.5 \mu \mathrm{F}$, $C_{A}$ of $7.6 \mu \mathrm{F}$, and $L$ of $0.8 \mathrm{mH}$. It can interrupt the fault current of $25 \mathrm{kA}$ within $3 \mathrm{~ms}$. The breaking performance and re-closure capability of the proposed DCCB are verified in a stiff DC model.

A $\pm 500 \mathrm{kV}$ four-terminal bipolar DC grid with the improved mechanical DCCB is tested. The simulation results for permanent pole-to-pole faults prove that the proposed DCCB can be well applied in the overhead DC grid. Two other simulations on the system in case of DCCBs malfunction show that the mechanical DCCB can work normally under extreme conditions and the energy absorption of the arrester would not be less than 103.91MJ. To further validate the effectiveness of the proposed DCCB, the experimental verification will be conducted in future work.

\section{ACKNOWLEDGMENTS}

This work is sponsored by the National Natural Science Foundation of China (51807071) and the Joint Funds of National Natural Science Foundation of China (U1766211), and the China Postdoctoral Science Foundation (2018M642840). 


\section{REFERENCES}

[1] Xiang W, Lin W, Xu L, Wen J. Enhanced independent pole control of hybrid MMC-HVDC system. IEEE Trans Power Del 2018; 33(2): 861-872.

[2] Elserougi A A, Abdel-Khalik A S, Massoud A M, et al. A new protection scheme for HVDC converters against DC-side faults with current suppression capability. IEEE Trans Power Del 2014; 29(4): 15691577

[3] Xiang W, Yang R, Lin C, et al. A Cascaded Converter Interfacing Long Distance HVDC and Back-toBack HVDC Systems. IEEE J Emerg Sel Topics Power Electron, 2019; early access, doi: 10.1109/JESTPE.2019.2913915.

[4] Lu X., Xiang W, Lin W., et al. Small-signal modeling of MMC based DC grid and analysis of the impact of DC reactors on the small-signal stability. Int J Electr Power Energy Syst 2018; 101: 25-37.

[5] Franck C M. HVDC circuit breakers: A review identifying future research needs. IEEE Trans Power Del 2011; 26(2): 998-1007.

[6] Cwikowski O, Chang B, Barnes M, et al. Fault current testing envelopes for VSC HVDC circuit breakers. IET Gener Transmiss Distrib 2016; 10(6): 1393-1400.

[7] Liu S, Popov M, Mirhosseini S, Nee S, et al. Modelling, Experimental Validation and Application of VARC HVDC Circuit Breakers. IEEE Trans Power Del. doi: 10.1109/TPWRD.2019.2947544 accepted for publication

[8] Ahmed N, Ängquist L, Mahmood S, et al. Efficient modeling of an MMC-based multiterminal DC system employing hybrid HVDC breakers. IEEE Trans Power Del 2015; 30(4): 1792-1801.

[9] Han X, Sima W, Yang M, et al. Transient characteristics under ground and short-circuit faults in a †500kV MMC-based HVDC system with hybrid DC circuit breakers. IEEE Trans Power Del 2018; 33(3): 1378-1387.

[10]Callavik M, Blomberg A, H“afner J, Jacobson B. The hybrid HVDC breaker-An innovation breakthrough enabling reliable HVDC grids. ABB Grid Syst, Tech Rep, pp. 1-10, Nov. 2012. 
[11]Häfner J, Jacobson B. Proactive Hybrid HVDC Breakers-A key innovation for reliable HVDC grids. Proc CIGRE Symp 2011: 1-9.

[12]Zhou W, Wei X, Zhang S, et al. Development and test of a 200kV full-bridge based hybrid HVDC breaker. 2015 17th European Conference on Power Electronics and Applications (EPE'15 ECCEEurope), Geneva. 2015. p. 1-7.

[13]Li B, Hao Q, Yin X. Study on Transient Electrical Characteristics of DC Circuit Breaker Based on IGBT Composite Model. 2018 IEEE International Power Electronics and Application Conference and Exposition (PEAC), Shenzhen. 2018. p. 1-5

[14]Pang H, Wei X. Research on key technology and equipment for Zhangbei 500kV DC Grid. 2018 International Power Electronics Conference, Niigata. 2018. p. 2343-2351.

[15]Zhangbei flexible HVDC project starts product bidding, [Online]. Available: http://pg.jrj.com.cn/acc/R es/CN_RES/INDUS/2018/4/1/79e33f53-42ec-473a-8e9f-4a390c398071.pdf

[16]Khorassani, M. Hybrid DC circuit breaking device. US 2015/0022928A1, 22 January, 2015.

[17]Zhou M, Xiang W, Zuo W, et al. A novel HVDC circuit breaker for HVDC application. Int J Electr Power Energy Syst 2019; 109: 685-695.

[18]Arimatsu K, Yoshioka Y, Tokuyama S, et al. Development and Interrupting Tests on 250kV 8KA HVDC Circuit Breaker. IEEE Trans Power App. and Syst, 1985(9): 2453-2459.

[19]Tahata K, El Oukaili S, Kamei K, et al. HVDC circuit breakers for HVDC grid applications. 11th IET ACDC Conference, Birmingham. 2015. p. 1-9.

[20]Shi Z Q, Zhang Y K, Jia S L, et al. Design and numerical investigation of a HVDC vacuum switch based on artificial current zero. IEEE Trans Dielectr Electr Insul 2015; 22(1): 135-141.

[21]Eriksson T, Backman M, Halen S. A low loss mechanical HVDC breaker for HVDC grid applications. Proc B4-303 CIGRE. 2014

[22]Bucher M K, Franck C M. Fault current interruption in multiterminal HVDC networks. IEEE Trans Power Del 2016; 31(1): 87-95. 
[23]Wu Y, Hu Y, Wu Y, et al. Investigation of an active current injection dc circuit breaker based on a magnetic induction current commutation module. IEEE Trans Power Del 2018; 33(4): 1809-1817.

[24]Liu L, Yuan Z, Xu H, et al. Design and test of a new kind of coupling mechanical HVDC circuit breaker. IET Gener Transmiss Distrib 2019; 13(9): 1555-1562.

[25]Liu S, Popov M. Development of HVDC system-level mechanical circuit breaker model. Int J Electr Power Energy Syst 2018; 103, 159-167.

[26]Wu Y, Wu Y, Yang F, et al. Bidirectional Current Injection MVDC Circuit Breaker: Principle and Analysis. IEEE J Emerg Sel Topics Power Electron 2018. (Early access)

[27]Wu Y, Wu Y, Yang F, et al. A Novel Current Injection DC Circuit Breaker Integrating Current Commutation and Energy Dissipation. IEEE J Emerg Sel Topics Power Electron 2019. (Early access)

[28]An T, Tang G, Wang W. Research and application on multi-terminal and DC grids based on VSC-HVDC technology in China. High Voltage 2017; 2(1): 1-10.

[29]Xiang W, Yang S, Xu L, et al. A Transient Voltage based DC Fault Line Protection Scheme for MMC based DC Grid Embedding DC Breakers. IEEE Trans on Power Del 2019; 34(1): 334-345.

[30]Phase Control Thyristor 5STP 08F6500. https://search-ext.abb.com/library/Download.aspx?Document ID=5SYA1056\&LanguageCode=en \&DocumentPartId=\&Action=Launch. 